Research Article

\title{
Comprehensive Evaluation of China's Prefabricated Decoration Cost Based on Analytic Hierarchy Process
}

\author{
Chunling Zhong, Mengqing Zhang, Xiao Cui $\mathbb{D}^{\mathrm{D}}$, and Zhe Liu \\ School of Economics and Management, Jilin Jianzhu University, Changchun 130000, China \\ Correspondence should be addressed to Xiao Cui; cui5214@126.com
}

Received 7 January 2020; Revised 15 October 2020; Accepted 7 December 2020; Published 15 December 2020

Academic Editor: Tayfun Dede

Copyright () 2020 Chunling Zhong et al. This is an open access article distributed under the Creative Commons Attribution License, which permits unrestricted use, distribution, and reproduction in any medium, provided the original work is properly cited.

\begin{abstract}
The development of China's construction industry is geared towards innovating traditional decoration engineering methods and promoting efficient, energy-saving and environmental-friendly prefabricated buildings. As an important part of prefabricated architecture, the slow development of prefabricated decoration has become one of the reasons that hinder the promotion and implementation of prefabricated architecture. The core problem of business is the high prefabricated cost. Accordingly, this study aims to construct a cost evaluation system with five first- and 22 second-level indices by using analytic hierarchy process (AHP). Then, the layer-by-layer analysis was conducted. Results show that the design stage has the highest weight in the first-level index, while the second-level index has the highest weight in the decoration scale assembly rate and costs of house type change, installation labor, and production, respectively, which have the most significant influence on the prefabricated decoration cost. Considering that China's prefabricated decoration has started late, this study uses China's prefabricated development as an example with the hope of providing reference for developing countries.
\end{abstract}

\section{Introduction}

Green development is one of the core values of high-quality development $[1,2]$. The pollution emission of the construction industry is deemed a serious problem, given that it is one of the industries to reduce energy consumption, pollution, and material consumption in China. The China Institute of Prospective Industry reported that "the construction waste that was generated in China has reached 2.379 billion tons in 2017, of which construction and decoration waste accounted for 6\%." The State Council of China has highly valued the advantages of resource and energy savings and pollution reduction in prefabricated buildings. Policies have been issued to promote the development of prefabricated buildings, such as "several opinions on deepening the construction of new urbanization and several opinions on further strengthening the management of urban planning and construction" [3]. As an important grasp of prefabricated building, prefabricated decoration is an important link and component of prefabricated building. The method's integrated production and dry operation are conducive to reducing labor consumption, construction waste, dust pollution, and harmful gas emissions in paint. The development of prefabricated decoration is the key factor to reducing energy consumption and pollution. At the same time, prefabricated decoration may also promote the construction industry's alignment with the concept of "One Belt and One Road" and sustainable development $[4,5]$.

In order to promote the practical application of prefabricated technology, researchers have conducted a lot of research on it, mechanization of assembly, and standardization of design, and it meets the requirements of green building. However, the incremental costs of prefabricated components brought by the application of prefabricated buildings are still higher than the drop in labor costs, building Information Modelling technology has played a positive role in solving this problem. Shuhai and Qing [6] think that prefabricated building has the advantages of mechanization of assembly and standardization of design and meets the requirements of green building. However, the 
incremental costs of prefabricated components brought by the application of prefabricated buildings are still higher than the drop in labor costs. Building Information Modelling technology has played a positive role in solving this problem. Satheeskumar et al. [7] have found that the number of prefabricated buildings is growing rapidly in developed countries, but in Australia, about $3 \%-4 \%$ of the new buildings every year are prefabricated buildings. They have carried out full-scale tests, numerical modelling, hybrid simulations, case studies, and social and economic assessments on prefabricated buildings to increase the market demand for prefabricated buildings in Australia and other countries. Yan et al. [8] Aimed to determine the hazard sources of prefabricated buildings in the production, transportation, on-site storage, and installation stages and used the method of expert investigation to evaluate the importance of hazard sources by using entropy weight method, determined the major hazard sources in each stage, and put forward corresponding suggestions. Linlin et al. [9] found that, in the EU, about $40 \%$ of energy consumption and $36 \%$ of carbon dioxide emissions come from buildings, and prefabricated buildings are an important way to achieve sustainable development. They use ANP method to obtain the comprehensive weight of the importance and performance of the critical sustainability aspects of the prefabricated building and determine the priority of project management for decision makers and relevant managers. Wasana et al. [10] compared the performance of prefabricated construction projects with those of traditional construction projects. The results show that the performance of prefabricated construction projects is lower than that of traditional construction projects in terms of time, cost, and quality performance. However, it is found that the performance of prefabricated construction projects in terms of health and safety standards is good. Prefabricated decoration is an important part of prefabricated buildings. These literatures have studied prefabricated buildings, but they have not studied the important link of decoration cost control.

AHP is a mathematical analysis method that is widely used and can be used to make decisions. Suhandi et al. [11] used the AHP to calculate multiple criteria to provide visitors in Saratiga with information and data on the location of cultural heritage to analyze the level of cultural heritage, ticket prices, popularity, etc., to provide convenience for tourists. Corsi et al. [12] used AHP to evaluate the standards and rank the final results. They believed that the selection of suppliers was one of the most critical activities in supply chain management and thus solved the problem in Malinga. Akhadun and Hidayat [13] used the AHP method in the complex process of selecting insurance products, comprehensively considering various factors in decision-making, including insurance, insurance period, and risk, and successfully helped decision makers find the best solution. Yeeun et al. [14] used the AHP to analyze the key factors affecting green infrastructure. The results of the analysis showed that the priority of creating green infrastructure requires further analysis and mediation among stakeholders, so as to effectively utilize the green infrastructure. Facilities solve the environmental problems of the city. Gerçek et al. [15] used the AHP to determine alternative energy sources in cities, which helped decision makers formulate long-term strategies for renewable energy development. This decision-making system has been applied in Chengdu, China, Ischichel, Turkey, and Chicago, USA. The results show that improving energy efficiency and developing solar and wind energy are the best alternative energy solutions for these three cities. However, through combing the above literature, we can find that the application of the AHP is very extensive, but we have not found the application of AHP to the evaluation of prefabricated decoration.

Herein, we apply the AHP method to the evaluation of the factors that affect the cost of prefabricated decoration. Using AHP as the research method, we divide the cost composition of prefabricated decoration into design, production, transportation, construction, or the operation and maintenance stages and use it as the first-level index of the evaluation method, and the specific influencing factors of each stage are analyzed and used as the second-level index. Through the establishment of the AHP model, the cost influencing factors of the prefabricated decoration were evaluated, and the measures to control the cost were proposed.

\section{Research Methods}

2.1. AHP Method. Prof. T. L. Saaty, an American operational research scientist in the early 1970s, put forward AHP [16-18]. AHP decomposes the decision-making problem and its influencing factors to form different index levels and conducts qualitative and quantitative analyses on each index at various levels. The AHP's characteristic is to establish a reasonable combination of qualitative and quantitative analyses and a hierarchical and quantitative analysis process for the decision-making problem [19, 20].

Numerous factors affect the comprehensive cost of prefabricated decoration. This study follows the following principles when screening indicators [21, 22]. (1) Feasibility refers to the required selected data approved by experts in the relevant fields. (2) Comprehensiveness refers to the selection of indicators at each level that must consider all factors affecting the comprehensive cost of prefabricated decoration as far as possible. (3) Hierarchy refers to the following: starting point from each stage of prefabricated decoration; the five stages running through prefabricated decoration selected for analysis, and five stages that are further subdivided as second-level indicators. (4) Independence refers to the indicators, which are as independent as possible with a small degree of correlation. (5) Comparability refers to the selected indicators, which should have a clear content and each index, which can be compared in pairs.

\subsection{Research Procedures}

Step 1: Establishing the hierarchical structure of the system. The latter is composed of the target layer and the first- and second-level indices. 
Step 2: Establishing the judgment matrix [23]. A judgment matrix is obtained via pairwise comparison of the importance of factors in the same layer relative to those in the previous layer. For example, the ratio of the relative importance of two factors $B_{i}$ and $B_{j}$ to a factor in the upper layer of a certain level is $a_{i j}$. The judgment matrix is $Y=\left(a_{i j}\right)_{n \times n}, " \mathrm{n}^{\prime \prime}$ is the matrix order, and Table 1 shows the value of $a_{i j}$.

Step 3: Calculating the weight. The column of the judgment matrix is normalized, and the row sum of the new matrix is calculated. Then, the column is normalized, and the obtained eigenvector $\|W\|[25]$ is the weight.

Step 4: Consistency test. Considering that some opinions have a strong subjective bias, testing the consistency of the judgment matrix is necessary. The maximum eigenvalue $\lambda \max$ is a single root and a positive real number. When $\lambda \max \geq n, \mathrm{Y}$ is consistent (when $\lambda \max <n C<0$, matrix unreasonable $\lambda_{\max }$ ) according to formula (1) obtained as follows:

$$
\lambda \max =\sum_{i=1}^{n} \frac{(Y W)_{i}}{n w_{i}} .
$$

The quantitative index used to measure the degree of matrix inconsistency is called the consistency index, which is recorded as " $\mathrm{C}$ " and defined as

$$
C=\frac{\lambda_{\max }-n}{n-1}
$$

When $C=0$, the judgment matrix is consistent. A high value of $C$ increases the seriousness in the inconsistency of the judgment matrix; however, when the random consistency index $C_{R}=(C / R) \leq 0.1$, the inconsistency of the judgment matrix remains acceptable, and the value of $R$ in the formula is as shown in Table 2.

2.3. Data Source and Model Construction. This study used a questionnaire survey [27-29] to compare the importance of each index in the above table with respect to a certain factor in the previous level. With the value of aij in Table 2 as the option, the questionnaire was distributed online. The questionnaire uses "questionnaire star" app to conduct online questionnaire survey. The detailed results of the questionnaire are the data sources of AHP calculation in this paper. The objects of the questionnaire survey are all managers engaged in prefabricated decoration and professors who study prefabricated decoration. A total of 152 responses were received, including 128 valid questionnaires, of which 75 were from professors and 53 from frontline managers. Given that the mode represents the central tendency of the view on the importance of a certain factor, the number of each option in the results of the valid questionnaire is used as the data used in constructing the judgment matrix of AHP. Considering the objectivity of the questionnaire, according to the reading time of the questionnaire for professors and frontline managers, we consider the questionnaire completed within 1 minute as invalid (the average reading time of the remaining valid questionnaires was 430.5781s).

Based on the characteristics of AHP and the present situation of prefabricated decoration, the factors affecting the comprehensive cost of prefabricated decoration are divided into five stages, namely, design, production, transportation, construction, and operation and maintenance [30]. Each stage is subdivided to form a complete analysis model as shown in Table 3.

\section{Empirical Analysis}

3.1. Weight Calculation. According to the analysis of the survey results by AHP, the comprehensive cost factors affecting the prefabricated decoration are empirically analyzed.

Step 1: Establishing a hierarchy. According to the five stages in Table 3, the first-level indicators were established, followed by the second-level indicators according to the 22 factors contained therein.

Step 2: Constructing a judgment matrix. According to the grading scale of Table 2 in the questionnaire, the importance of the five first-level indicators and 22 second-level indicators involved in this study on the comprehensive cost of assembly and decoration was judged [31-33]. The importance judgment matrix of Level 1 index, $Y_{1}, Y_{2}, Y_{3}, Y_{4}$, and $Y_{5}$ relative to the comprehensive cost influencing factor of prefabricated decoration and the importance judgment matrix of $Y$ are shown in Table 4; Tables 5-9 are the five judgment matrices of each secondary indicator to the primary indicator. The weight calculation and consistency testing process of the first- and the second-level indicators are as follows:

On the basis of the expert scoring results, Table 4 shows the judgment matrix of first-level indicators.

Step 3: Based on the judging matrix Table 4 and the weight calculation process described above, $W=(0.4107,0.2126,0.0416,0.1796,0.1555)^{T}$, and $T$ is the matrix transposition symbol.

Step 4: The maximum eigenvalues of the judgment matrix $Y$ can be obtained by calculating

$$
\lambda \max =\sum_{i=1}^{n} \frac{(Y W)_{i}}{n w_{i}}=5.4224,
$$

where $C=\left(\lambda_{\max }-n / n-1\right)==(5.4224-5) /(5-1)=$ 0.1056 was obtained according to formula (2), while the random consistency ratio is denoted by

$$
\begin{aligned}
C_{R} & =\frac{C}{R}, \\
& =\frac{0.1056}{1.12}, \\
& =0.0943<0.1 .
\end{aligned}
$$


TABLE 1: Saaty's nine-point intensity scale [24].

\begin{tabular}{lr}
\hline Scale & Judgments of preferences \\
\hline 1 & Equally important \\
3 & Slightly strong \\
5 & Strong \\
7 & Very strong \\
9 & Absolutely strong \\
$1 / 3$ & Slightly weak \\
$1 / 5$ & Weak \\
$1 / 7$ & Very weak \\
$1 / 9$ & Absolutely weak \\
\hline
\end{tabular}

TABLE 2: R set value [26].

\begin{tabular}{cccccccccc}
\hline $\mathrm{N}$ & 3 & 4 & 5 & 6 & 7 & 8 & 9 & 10 & 11 \\
\hline $\mathrm{R}$ & 0.58 & 0.90 & 1.12 & 1.24 & 1.32 & 1.41 & 1.45 & 1.49 & 1.51 \\
\hline
\end{tabular}

Note. $n$ is the order of the judgment matrix, and the matrix is completely consistent when the matrix is a first- or second-order matrix.

TABLE 3: Factors affecting the cost of prefabricated decoration.

\begin{tabular}{|c|c|}
\hline First-grade indicator & Level II indicator \\
\hline Design phase $\left(\mathrm{Y}_{1}\right)$ & $\begin{array}{c}\text { Assembly style }\left(X_{11}\right) \\
\text { Assembly scale }\left(X_{12}\right) \\
\text { Assembly rate }\left(X_{13}\right) \\
\text { Rationality of component separation }\left(X_{14}\right) \\
\text { Repeating utilization factor }\left(X_{15}\right)\end{array}$ \\
\hline Production phase $\left(\mathrm{Y}_{2}\right)$ & $\begin{array}{c}\text { Raw material cost }\left(X_{21}\right) \\
\text { Production costs (labor and water and electricity consumption) }\left(X_{22}\right) \\
\text { Production engineering }\left(X_{23}\right) \\
\text { Factory amortization fee }\left(X_{24}\right) \\
\text { Factory profit }\left(X_{25}\right)\end{array}$ \\
\hline Transportation phase $\left(\mathrm{Y}_{3}\right)$ & $\begin{array}{c}\text { Traffic expense }\left(X_{31}\right) \\
\text { Packing charges }\left(X_{32}\right) \\
\text { Loading and unloading fees }\left(X_{33}\right) \\
\text { Storage costs }\left(X_{34}\right)\end{array}$ \\
\hline Construction phase $\left(\mathrm{Y}_{4}\right)$ & $\begin{array}{c}\text { Installation labour costs }\left(X_{41}\right) \\
\text { Installation of accessories }\left(X_{42}\right) \\
\text { Machinery costs }\left(X_{43}\right) \\
\text { Amortization of special tools }\left(X_{44}\right)\end{array}$ \\
\hline Operation and maintenance phase $\left(\mathrm{Y}_{5}\right)$ & $\begin{array}{c}\text { Household type change cost }\left(X_{51}\right) \\
\text { Cost of hydropower pipeline changes }\left(X_{52}\right) \\
\text { Cost of water and electricity pipeline maintenance }\left(X_{53}\right) \\
\text { Demolition and waste removal costs }\left(X_{54}\right)\end{array}$ \\
\hline
\end{tabular}

Therefore, the phases of design, production, transportation, construction, and operation and maintenance on the cost impact of the installation decoration of the weight are $0.4107,0.2126,0.0416,0.1796$, and 0.1555 , respectively.

According to the expert scoring results, Table 5 shows the level 2 indicator judgment matrix in the design phase.

The above calculation steps are repeated to determine the maximum eigenvalue of matrix, shown in Table $5, \lambda \max =$ 5.3603. The corresponding feature vector is $W=(0.1737$, $0.4334,0.2542,0.0899,0.0488)^{T}, C=0.0901, C_{R}=0.0804$ $<0.1$; that is, the relative weight of assembly style, assembly scale, assembly rate, rationality of component separation, and repeating utilization factor on costs during the design phase are $0.1737,0.4334,0.2542,0.0899$, and 0.0488 , respectively.

According to the expert scoring results, Table 6 presents the Level 2 indicator judgment matrix in the production phase.

The maximum eigenvalue of judgment matrix is shown in Table 6, $\lambda \max =5.372$, and the corresponding eigenvector $W=(0.2850,0.3960,0.2221,0.0471,0.0498)^{T}$, $C=0.0930, C_{R}=0.0830<0.1$; that is, the relative weight of raw material cost, production costs (labor and water and electricity consumption), production engineering, factory amortization fees, and the impact of factory profits on costs during the production phase are 0.2850, 0.3960, 0.2221, 0.0471 , and 0.0498 , respectively. 
TABLE 4: Level I index judgment matrix on the comprehensive cost factor of prefabricated decoration.

\begin{tabular}{cccccc}
\hline $\mathrm{Y}$ & $\mathrm{Y}_{1}$ & $\mathrm{Y}_{2}$ & $\mathrm{Y}_{3}$ & $\mathrm{Y}_{4}$ & $\mathrm{Y}_{5}$ \\
\hline $\mathrm{Y}_{1}$ & 1 & 3 & 5 & 3 & 3 \\
$\mathrm{Y}_{2}$ & $1 / 3$ & 1 & 5 & 1 & 3 \\
$\mathrm{Y}_{3}$ & $1 / 5$ & $1 / 5$ & 1 & $1 / 7$ & $1 / 7$ \\
$\mathrm{Y}_{4}$ & $1 / 3$ & 1 & 7 & 1 & 1 \\
$\mathrm{Y}_{5}$ & $1 / 3$ & $1 / 3$ & 7 & 1 & 1 \\
\hline
\end{tabular}

TABLE 5: Judgment matrix of the design phase.

\begin{tabular}{lccccc}
\hline$Y_{1}$ & $X_{11}$ & $X_{12}$ & $X_{13}$ & $X_{14}$ & $X_{15}$ \\
\hline$X_{11}$ & 1 & $1 / 3$ & $1 / 3$ & 3 & 5 \\
$X_{12}$ & 3 & 1 & 3 & 5 & 5 \\
$X_{13}$ & 3 & $1 / 3$ & 1 & 3 & 5 \\
$X_{14}$ & $1 / 3$ & $1 / 5$ & $1 / 3$ & 1 & 3 \\
$X_{15}$ & $1 / 5$ & $1 / 5$ & $1 / 3$ & $1 / 3$ & 1 \\
\hline
\end{tabular}

TABLE 6: Judgment matrix of the production phase.

\begin{tabular}{lccccc}
\hline$Y_{2}$ & $X_{21}$ & $X_{22}$ & $X_{23}$ & $X_{24}$ & $X_{25}$ \\
\hline$X_{21}$ & 1 & 1 & 1 & 5 & 7 \\
$X_{22}$ & 1 & 1 & 5 & 7 & 5 \\
$X_{23}$ & 1 & $1 / 5$ & 1 & 5 & 7 \\
$X_{24}$ & $1 / 5$ & $1 / 7$ & $1 / 7$ & 1 & 1 \\
$X_{25}$ & $1 / 7$ & $1 / 5$ & $1 / 5$ & 1 & 1 \\
\hline
\end{tabular}

According to the expert scoring results, Table 7 shows the Level 2 indicator judgment matrix for the transportation phase.

The maximum eigenvalue of judgment matrix is shown in Table 7, $\lambda \max =4.2668$, and the corresponding eigenvector $W=(0.5402,0.0610,0.2090,0.1898)^{T}, \quad C=$ $0.0889, C_{R}=0.0988<0.1$; that is, the relative weight of traffic, packaging, loading and unloading, and storage costs on transport phase in the transportation phase are 0.5402 , $0.0610,0.2090$, and 0.1898 , respectively.

According to the expert scoring results, Table 8 presents the Level 2 indicator judgment matrix for the construction phase.

The maximum eigenvalue of judgment matrix is shown in Table $8, \lambda \max =4.1554$, and the corresponding eigenvector $W=(0.4812,0.0980,0.2104,0.2104)^{T}, \quad C=$ $0.0518, C_{R}=0.0576<0.1$; that is, the relative weight of the cost impact of installation labor cost, installation of accessories, machinery costs, and amortization of special tools in the construction phase are 0.4812, 0.0980, 0.2104, and 0.2104 , respectively.

According to the expert scoring results, Table 9 presents the Level 2 indicator judgment matrix for the operation and maintenance phase.

The maximum eigenvalue of judgment matrix is shown in Table 9, $\lambda \max =4.1165$, and the corresponding eigenvector $W=(0.5873,0.2315,0.0593,0.1219)^{T}, \quad C=$ $0.0388, C_{R}=0.0431<0.1$; that is, the relative weight of the household type change costs, cost of hydropower pipeline changes, cost of water and electricity pipeline maintenance, and demolition and waste removal costs in the operation and maintenance stage are $0.5873,0.2315,0.0593$, and 0.1219 , respectively.

The absolute weight of the effect of the secondary indicators on prefabricated cost is calculated according to the relative weight of each secondary indicator as shown in Table 10. Through the pie chart of Figures 1 and 2, it can be clearly and intuitively reflected.

3.2. Reliability Test. In order to verify the correctness of the above results, this paper adopts the form of a second questionnaire, inviting 30 industry famous experts besides the first questionnaire. The questionnaire gave feedback to the contents in Table 10, and the experts judged and selected the results according to their practical experience and original opinions. The judgment result is as follows: agree, basically agree, and disagree. Figure 3 shows the results of the second questionnaire survey. According to the results of the second questionnaire, we can judge that Table 10 is consistent with the results of the second questionnaire.

\section{Results and Discussion}

4.1. Detail of Factors Local/Global Weight. The weights of the first- and the second-level indicators are arranged in the phases of design, production, construction, operation and maintenance, and transportation as shown in Table 10. Results show that the design phase is the most important indicator among the first-level indicators that affect the comprehensive cost of prefabricated decoration. The proportion is as high as 0.4107 because the aim is to reduce the initial stages of prefabricated decoration cost, the quality of each stage of the implementation plays a vital role, and a prefabricated decoration project can control the cost of the fundamental factor. The second is the index of the production stage, with a weight of 0.2126 , indicating that the production stage is an important bottleneck to control prefabricated decoration, improve production efficiency and component accuracy, and simplify the production process. The latter also is an important part of controlling the cost of prefabricated decoration. The third is the construction phase index, with a weight of 0.1796 , indicating that although the construction difficulty is low and the duration is short, the labor and mechanical costs generated during the construction phase remain the inevitable problem in controlling the cost of prefabricated decoration. Ranked fourth are the operation and maintenance phase indicators with a weight of 0.1555 , and the huge scale of the construction industry decided that its late operation and maintenance costs are sufficient to attract people's attention; thus, it occupies a lower proportion. The transport phase indicators rank fifth. The cost of this stage is lower than the weight of the other four first-level indices, thereby rendering its share as the smallest. Nonetheless, through the rational planning of transport routes, storage locations and other means can also reduce the cost of prefabricated decoration at this stage.

The importance of the overall cost impact of the calculated secondary indicators on the prefabricated decoration can be seen as follows: the decoration scale, assembly rate, 
TABLE 7: Judgment matrix of the transport phase.

\begin{tabular}{lcccc}
\hline$Y_{3}$ & $X_{31}$ & $X_{32}$ & $X_{33}$ & $X_{34}$ \\
\hline$X_{31}$ & 1 & 5 & 3 & $1 / 5$ \\
$X_{32}$ & $1 / 5$ & 1 & 1 & $1 / 5$ \\
$X_{33}$ & $1 / 3$ & 5 & 1 & 1 \\
$X_{34}$ & $1 / 5$ & 5 & 1 \\
\hline
\end{tabular}

TABLE 8: Judgment matrix of the construction phase.

\begin{tabular}{lcccc}
\hline$Y_{4}$ & $X_{41}$ & $X_{42}$ & $X_{43}$ & $X_{44}$ \\
\hline$X_{41}$ & 1 & 3 & 3 & 3 \\
$X_{42}$ & $1 / 3$ & 1 & $1 / 3$ & $1 / 3$ \\
$X_{43}$ & $1 / 3$ & 3 & 1 & 1 \\
$X_{44}$ & $1 / 3$ & 3 & 1 & 1 \\
\hline
\end{tabular}

TABLE 9: Judgment matrix of the operation and maintenance phase.

\begin{tabular}{lcccc}
\hline$Y_{5}$ & $X_{51}$ & $X_{52}$ & $X_{53}$ & \\
\hline$X_{51}$ & 1 & 3 & 9 & $X_{54}$ \\
$X_{52}$ & $1 / 3$ & 1 & 3 & 3 \\
$X_{53}$ & $1 / 9$ & $1 / 3$ & 1 & $1 / 3$ \\
$X_{54}$ & $1 / 5$ & $1 / 3$ & 3 & 1 \\
\hline
\end{tabular}

TABLE 10: Evaluation system and weight of indicators at all levels of the cost of prefabricated decoration.

\begin{tabular}{|c|c|c|c|c|}
\hline Level I indicator & Weight & Level II indicator & Local weights & Global weights \\
\hline$Y_{1}$ & 0.4107 & $\begin{array}{l}X_{11} \\
X_{12} \\
X_{13} \\
X_{14} \\
X_{15}\end{array}$ & $\begin{array}{l}0.1737 \\
0.4334 \\
0.2542 \\
0.0899 \\
0.0488\end{array}$ & $\begin{array}{l}0.0713 \\
0.1780 \\
0.1044 \\
0.0369 \\
0.0200\end{array}$ \\
\hline$Y_{2}$ & 0.2126 & $\begin{array}{l}X_{21} \\
X_{22} \\
X_{23} \\
X_{24} \\
X_{25} \\
\end{array}$ & $\begin{array}{l}0.2850 \\
0.3960 \\
0.2221 \\
0.0471 \\
0.0498\end{array}$ & $\begin{array}{l}0.0606 \\
0.0842 \\
0.0472 \\
0.0100 \\
0.0106\end{array}$ \\
\hline$Y_{3}$ & 0.0416 & $\begin{array}{l}X_{31} \\
X_{32} \\
X_{33} \\
X_{34} \\
\end{array}$ & $\begin{array}{l}0.5402 \\
0.0610 \\
0.2090 \\
0.1898 \\
\end{array}$ & $\begin{array}{l}0.0225 \\
0.0025 \\
0.0087 \\
0.0079 \\
\end{array}$ \\
\hline$Y_{4}$ & 0.1796 & $\begin{array}{l}X_{41} \\
X_{42} \\
X_{43} \\
X_{44} \\
\end{array}$ & $\begin{array}{l}0.4812 \\
0.0980 \\
0.2104 \\
0.2104 \\
\end{array}$ & $\begin{array}{l}0.0864 \\
0.0176 \\
0.0378 \\
0.0378 \\
\end{array}$ \\
\hline$Y_{5}$ & 0.1555 & $\begin{array}{l}X_{51} \\
X_{52} \\
X_{53} \\
X_{54}\end{array}$ & $\begin{array}{l}0.5873 \\
0.2315 \\
0.0593 \\
0.1219\end{array}$ & $\begin{array}{l}0.0913 \\
0.0360 \\
0.0092 \\
0.0190\end{array}$ \\
\hline
\end{tabular}

household type change cost, installation labor cost, and production cost are the top five factors in the absolute weight, accounting for $54.4 \%$ of the importance weight of the influencing factors of prefabricated decoration comprehensive cost. Controlling the comprehensive cost of prefabricated decoration from the above analysis results is necessary, and we must seize these five key factors as a major breakthrough to reduce the comprehensive cost of prefabricated decoration.

\subsection{Detail of Subfactors Local Weights}

4.2.1. Design Phase. For the design phase, experts stated that the "assembly scale" (0.4334) is the priority, followed by 

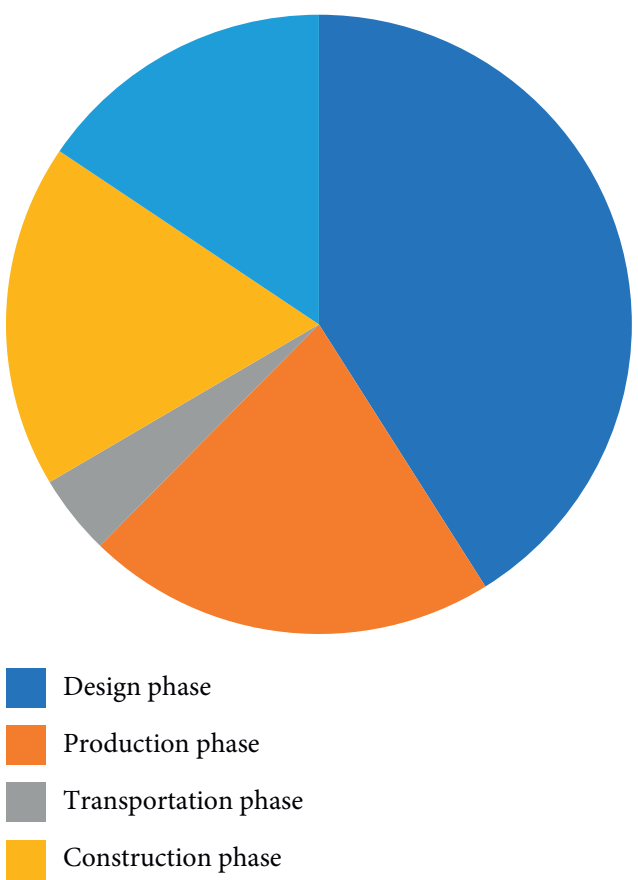

Operation and maintenance phase

FIGURE 1: Weights of level I.

“assembly rate” (0.2542), “assembly style" (0.1737), "rationality of component separation" (0.0899), and "repeating utilization factor" (0.0488), which is the lowest weighting factor at this stage. Results show that the most effective means of controlling cost in the design phase is in the assembly scale. However, the lack of design technology on the rationality of component splitting and the reuse ratio will limit the effect of controlling costs.

4.2.2. Production Phase. Table 10 shows that "production costs" (0.3960) account for the highest weighting in the production phase, followed by "raw material cost" (0.2850), and then "production engineering" (0.2221). China's prefabricated component production plant standardization is not that high, and so is the input of machinery and labor in the production process. Thus, increasing the research and development of production technology in the later stage is an effective choice.

4.2.3. Transport Phase. The transportation phase includes transportation, packaging, handling, and storage. According to the three-level analysis, the "traffic expense" (0.5402) and "loading and unloading fees" (0.2090) have accounted for the highest proportion, followed by "storage costs" (0.1898), and then "packing charges" (0.0610). In the transportation phase, transportation costs occupy such a large proportion because the current prefabricated component factories in China are few. Moreover, the distance to transport the prefabricated components to the construction site is typically long, and the components are generally large.
Therefore, strict control is an effective method of reducing transportation cost.

4.2.4. Construction Phase. In the construction phase, the "installation labor costs" (0.4812) accounted for a large proportion, of which "mechanical costs" (0.2104) and "amortization of special tool" (0.2104) accounted for the same proportion, whereas the proportion of "installation accessories" (0.0980) is relatively small. The installation labor costs account for such a large proportion because the current labor costs are high. Given that some installation materials can be reused, they are relatively low. If they are well managed, the cost of this phase can be substantially reduced.

4.2.5. Operation and Maintenance Phase. The operation and maintenance phase comprises four subfactors. According to the ranking of their weights, "household type change cost" (0.5873) and "cost of hydropower pipeline changes" (0.2315) have accounted for a larger share, followed by "demolition and waste removal costs" (0.1219) and "Maintenance cost of hydropower pipeline" (0.0593). According to the weight available, the change cost of house type and cost of water and electricity pipeline in the current operation stage have accounted for as much as $80 \%$ of the operation and maintenance cost in the later stage. This phenomenon is caused by the huge changes made to house type and room facilities, resulting in relatively high material and labor costs. Compared with the simple maintenance of the pipeline such as local changes, the operation and maintenance costs are much higher.

4.3. Detail of Subfactors of the Global Weights. According to the order of absolute weight, assembly scale, assembly rate, household type change cost, installation labor, and production costs are the first five factors with the highest proportion of absolute weight. They account for $54.4 \%$ of the importance weight of the influencing factors of prefabricated decoration comprehensive cost. Therefore, they must grasp the five key factors as the main breakthrough to control the assembly of the overall decoration cost.

\section{Research Conclusions and Contributions}

5.1. Conclusions. Under the context of transformation exploration from traditional to prefabricated decoration, this study establishes the importance analysis system of the factors influencing the comprehensive cost of prefabricated decoration. Through this study, the following conclusions are drawn. First, the scale of prefabricated decoration is the key factor to control the cost of prefabricated decoration; a large scale is the premise of improving design and production standardization and an indispensable step in continuously improving the upstream and downstream industrial chain of prefabricated decoration. Therefore, the scale of prefabricated decoration is very important to control its cost. Second, the assembly rate is also a factor that cannot 


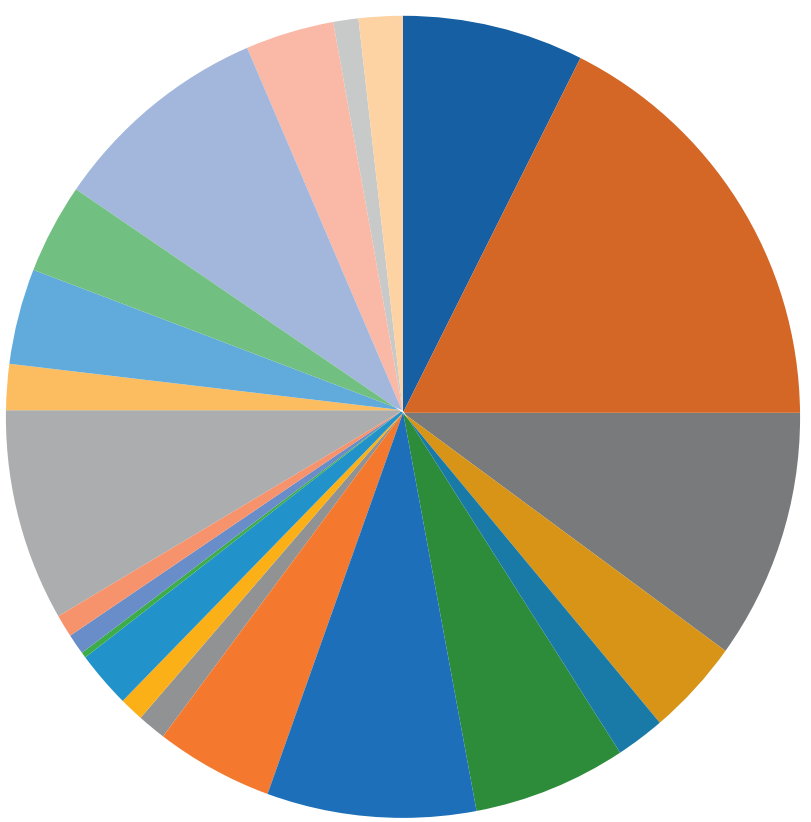

Assembly style

Assembly scale

Assembly rate

Rationally of component separation

Repeating utilization factor

Raw material cost

Production costs

Production engineering

Factory amortization fee

Factory profit

Traffic expense

Packing charges

Loading and unloading fees

Storage costs

Installation labor costs

Installation of accessories

Machinery costs

Amortization of special tools

Household type change cost

Cost of hydropower pipeline changes

Cost of water and electricity pipeline maintenance

Demolition and waste removal costs

Figure 2: Global weights of Level II.

be ignored in the cost control of prefabricated decoration. Prefabricated decoration should be applied in practice. However, the "how much to use" subfactor remains a problem because of its incapacity to combine the actual technical level and the accurate design of building structure. Moreover, the assembly rate is either too high or too low, thereby rendering it disadvantageous to the control cost. Third, the household type change cost is also included in the

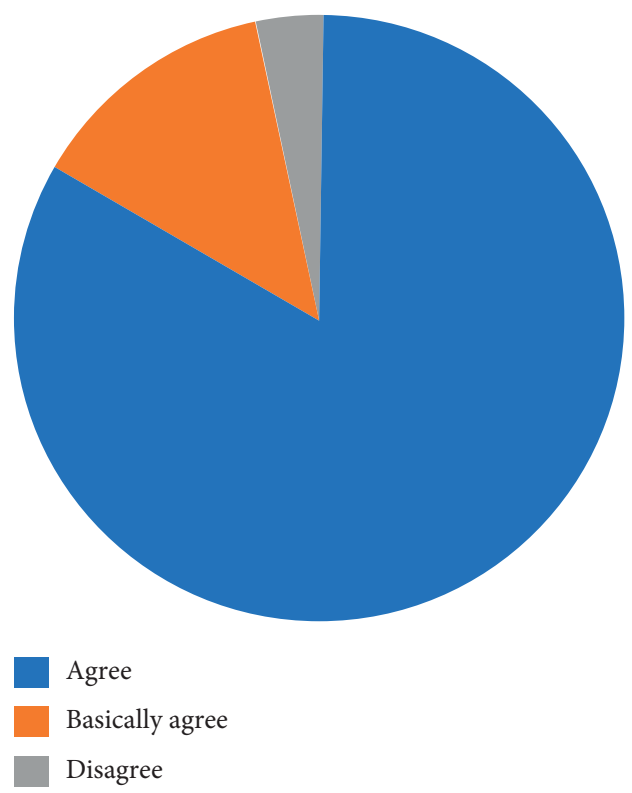

FIgURE 3: Results of the second questionnaire survey.

necessary consideration of the decoration cost by the owner. Reducing the difficulty of household type change and shortening the household type change period are the necessary means to control the cost of assembly decoration in the operation and maintenance stage. Fourth, the installation labor and production costs continue to serve as the influencing factors in the construction industry while occupying a large proportion in the analysis of this study. However, reducing the labor costs in each stage of the construction industry is difficult due to the increase in workers with undefined basic wages and social security.

\subsection{Research Contribution}

(1) Expanding prefabricated decoration scale will reduce the costs [34]. Thus, we should vigorously develop prefabricated decoration. First, we should expand the market on prefabricated decoration, form the market mechanism of part system design and production specialization, commercialize the supply of parts and components, and closely combine design and production with market demand. For example, for parts of kitchens, bathrooms, and so on, which are relatively solidified in function [35], design units and production enterprises can conduct large-scale standardized designs and production. However, in the pursuit of high-quality and multistyle decoration parts, they should properly improve the diversification of the design. Second, actively popularizing the collaborative design of the prefabricated decoration part system and the prefabricated building structure is important to form a supporting modulus coordination system and a part system of standard design, scale production, supporting supply, module coordination, and technical integration. Finally, the design and production should 
be in line with the development level of urban construction, and some parts of the system with a balance between standardization and diversification should be established in accordance with the local conditions; such process enables the development of the city to adapt to the local economies of scale.

(2) Using the minimum assembly rate set by local policy as the minimum standard and considering the economic assembly rate: through a threedimensional simulation in the design stage, the amount of decoration projects under different assembly rates is determined, and the price of the components used in decoration is also determined via inquiry. According to the valuation code of decoration engineering, the decoration cost under various assembly rates is calculated, and the curve of decoration cost changes when the assembly rate is drawn. Given that the assembly rate may change due to uncontrollable factors in the decoration process, the assembly rate interval with a relatively flat trend of cost increment should be selected, because it will not cause a large increase in costs; consequently, the assembly rate will have a certain variable space, and the average cost in the selected interval will be relatively low.

(3) A three-dimensional prechange is conducted using simulation technology. Before the transformation of the household type, the size of the household type requires accurate measurement; moreover, the threedimensional pretransformation should be carried out by using Revit3D model software to determine the size of the parts used, reserve the location of holes, conduct accurate construction, and achieve the goal in only one step to reduce the cost of rework. Improving the standardization level of prefabricated and decorated parts is beneficial for the owner to purchase the parts suitable for residential decoration during the transformation [36]. Doing so avoids the cost of customization due to the lack of components of a suitable size in the market. Completing the indoor decoration as scheduled after the household type change is completed is also possible to reduce the cost within the duration of the construction period.

\section{Data Availability}

The data generated in this research are available from the corresponding author on request.

\section{Conflicts of Interest}

The authors declare that they have no conflicts of interest.

\section{Authors' Contributions}

Conceptualization was performed by C. Z. and M. Z.; methodology was done by C. Z. and M. Z.; validation was done by M. Z. and X. C.; formal analysis was performed by M. Z. and Z. L.; investigation was done by C. Z. and M. Z.; original draft preparation was performed by C. Z. and M. Z.; reviewing and editing were performed by X. C. and Z. L.; project administration was performed by X. C.; Z. L. was responsible for funding acquisition.

\section{Acknowledgments}

The authors wish to thank the anonymous reviewers for their constructive suggestions and comments to improve the quality of this paper. This research was funded by the Department of Science and Technology of Jilin Province (grant no. 2019061070FG)

\section{References}

[1] A. D. Alsulaili, M. F. Al-Matrouk, R. A. Al-Baghli, and A. F. Al-Enezi, Envieonmental and Economic Benefits of Applying Green Building Concepts in Kuwait, Springer Nature B. V., Berlin, Germany, 2019.

[2] S. Shao, R. Luan, Z. Yang, and C. Li, "Does directed technological change get greener: empirical evidence from Shanghai's industrial green development transformation," Ecological Indicators, vol. 69, pp. 758-770, 2016.

[3] Ministry of Housing and Urban-Rural Development of the China, China Assembly Building Development Report, Ministry of Housing and Urban-Rural Development of the China, Yunnan, China, 2017, in Chinese.

[4] O. Oscar, C. Francesc, and S. Guido, "Sustainability in the construction industry: a review of recent developments based on LCA," Construction and Building Materials, vol. 23, pp. 28-39, 2009.

[5] D. Liang, Y. Xiaohua, and L. Hongtao, "The Belt and Road initiative and the 2030 agenda for sustainable development: seeking linkages for global environmental governance," Chinese Journal of Population Resources and Environment, vol. 16, no. 3, pp. 203-210, 2018.

[6] W. Shuhai and L. Qing, "Analysis on the application of BIM and RFID in life cycle management of prefabricated building," Materials Science and Engineering, vol. 780, pp. 1-5, 2020.

[7] N. Satheeskumar, N. Tuan, G. Tharaka, and H. David, "Performance review of prefabricated building systems and future research in Australia," Buildings, vol. 9, no. 38, pp. 1-14, 2019.

[8] L. Yan and C. Jialin, "Identification of hazard sources in prefabricated building construction by entropy weight method," Earth and Environmental Science, vol. 560, pp. 1-7, 2020.

[9] X. Linlin, C. Yajiao, X. Bo, and H. Chunxiang, "Importanceperformance analysis of prefabricated building sustainability: a case study of guangzhou," Advances in Civil Engineering, vol. 2020, 17 pages, 2020.

[10] K. H. I. Wasana, G.. Sachie, and M. F. F. Fasna, "Performance comparison of prefabricated building construction projects vs. Traditional on-site construction projects," in Proceedings of the Moratuwa Engineering Research Conference, pp. 169174, Moratuwa, Sri Lanka, July 2019.

[11] N. E. Suhandi, K. D. Hartomo, and P. Fiodinggo Tanaem, "Rancang bangun sistem informasi geografis rekomendasi cagar budaya menggunakan metode analytic hierarchy process," Jurnal Teknik Informatika Dan Sistem Informasi, vol. 6, no. 2, pp. 222-233, 2020. 
[12] A. Corsi, D. H. Barbosa, and A. M. K. Moro, "Aplicação da metodologia analytic hierarchy process para seleção de fornecedores em uma indústria de confecção," Navus-Revista de Gestão e Tecnologia, vol. 10, pp. 01-20, 2020.

[13] A. A. Akhadun and A. Hidayat, "Sistem pendukung keputusan pemilihan produk asuransi berbasis web menggunakan metode AHP (analytic hierarchy process) studi kasus BRI life semarang," Jurnal Informatika dan Rekayasa Perangkat Lunak, vol. 2, pp. 49-56, 2020.

[14] S. Yeeun, K. Suyeon, L. Sang-Woo, and A. Kyungjin, "Identifying the planning priorities for green infrastructure within urban environments using analytic hierarchy process," Sustainability, vol. 12, pp. 1-13, 2020.

[15] B. Gerçek, C. Xin, C. Serdar, and O. Berk, "A systematic approach for assessment of renewable energy using analytic hierarchy process," Energy, Sustainability and Society, vol. 201914 pages, 2019.

[16] R. W. Saaty, "The analytic hierarchy process-what it is and how it is used," Mathematical Modelling, vol. 9, no. 3-5, pp. 161-176, 1987.

[17] P. Aragonés-Beltrán, F. Chaparro-González, J.-P. PastorFerrando, and A. Pla-Rubio, "An AHP (analytic hierarchy process)/ANP (analytic network process)-based multi-criteria decision approach for the selection of solar-thermal power plant investment projects," Energy, vol. 66, pp. 222-23810, 2014.

[18] T. L. Saaty, "Decision making with the analytic hierarchy process," International Journal of Services Sciences, vol. 1, no. 1, pp. 83-98, 2008.

[19] D. Choudhary and R. Shankar, "An steep-fuzzy AHP-TOPSIS framework for evaluation and selection of thermal power plant location: a case study from India," Energy, vol. 42, no. 1, pp. 510-521, 2012.

[20] S. P. Sindhu, V. Nehra, and S. Luthra, "Recognition and prioritization of challenges in growth of solar energy using analytical hierarchy process: Indian outlook," Energy, vol. 100, pp. 332-348, 2016.

[21] M. Uyan, "GIS-based solar farms site selection using analytic hierarchy process (AHP) in Karapinar region, Konya/Turkey," Renewable and Sustainable Energy Reviews, vol. 28, pp. 11-17, 2013.

[22] I. Talinli, E. Topuz, E. Aydin, and S. B. Kabakc1, "A holistic approach for wind farm site selection by FAHP," Wind Farm: Technical Regulations, Potential Estimation and Siting Assessment, vol. 14, pp. 213-234, 2011.

[23] G. Khan and S. Rathi, "Optimal site selection for solar PV power plant in an Indian state using geographical information system (GIS)," International Journal of Emerging Engineering Research and Technology, vol. 2, no. 7, pp. 260-266, 2014.

[24] C. Prakash and M. K. Barua, "Integration of AHP-TOPSIS method for prioritizing the solutions of reverse logistics adoption to overcome its barriers under fuzzy environment," Journal of Manufacturing Systems, vol. 37, pp. 599-615, 2015.

[25] L. S. Thomas, Decision-making with the AHP: Why Is the Principal Eigenvector Necessary, vol. 2, pp. 85-87, Elsevier, Amsterdam, Netherlands, 2003.

[26] T. L. Saaty, Fundamentals of Decision Making and Priority Theory with the Analytic Hierarchy Process, Vol. 6, Rws Publications, Pittsburgh, PA 15213, USA, 2000.

[27] D. Magnus, S. Rodgers, A. J. Avery et al., "GPs' views on computerized drug interaction alerts: questionnaire survey," Journal of Clinical Pharmacy and Therapeutics, vol. 27, no. 5, pp. 377-382, 2002.
[28] A. Janca, M. Isaac, L. A. Bennett, G. Tacchini, and L. A. Tacchini, "Somatoform disorders in different cultures?a mail questionnaire survey," Social Psychiatry and Psychiatric Epidemiology, vol. 30, no. 1, pp. 44-48, 1995.

[29] Q. Lyn, "Workplace bullying in NHS community trust: staff questionnaire survey," BMJ, vol. 318, pp. 228-232, 1999.

[30] J. Hongjun and X. Yunping, "Research on cost-based construction cost management based on analytic hierarchy," Building Economy, vol. 7, pp. 79-83, 2018, in Chinese.

[31] T. S. C Felix and K. Niraj, "Global supplier development considering risk factors using fuzzy extended AHP-based approach," Omega, vol. 35, pp. 417-431, 2007.

[32] W. Chun-Chin, C. Chen-Fu, and J. W. Mao-Jiun, "An AHPbased approach to ERP system selection," International Journal of Production Economics, vol. 96, pp. 47-62, 2005.

[33] C. Macharis, J. Springael, K. De Brucker, and A. Verbeke, "PROMETHEE and AHP: the design of operational synergies in multicriteria analysis. Strengthening PROMETHEE with ideas of AHP," European Journal of Operational Research, vol. 153, pp. 307-317, 2004.

[34] P. Newman, New Palgrave Dictionary of EconomicsEconomic Science Press, Washington, DC, USA, first Edition, translated by Chen Daisun et al, pp. 638-639, 1996.

[35] Y. Jing and F. Wenwu, "Housing diversification design strategy under the background of standardization of industrial building evaluation: taking Nanjing Dingjiazhuang Phase II A27 Public Rental Housing Project as an example," Times Architecture, vol. 4, pp. 170-177, 2017, in Chinese.

[36] Y.. MaoYuan, "Study on BIM + assembly type $+3 \mathrm{~d}$ printing complex," Focus on Informatization, vol. 37, pp. 76-79, 2019, in Chinese. 